\title{
Potential Map for the Installation of Concentrated Solar Power in Northeast of Brazil Using Analytic Hierarchy Process (AHP)
}

\author{
Chigueru Tiba, Verônica W. B. Azevêdo \\ Departmento de Energia Nuclear, Universidade Federal de Pernambuco, Recife, Brazil \\ Email: tiba@ufpe.br
}

How to cite this paper: Tiba, C. and Azevêdo, V.W.B. (2020) Potential Map for the Installation of Concentrated Solar Power in Northeast of Brazil Using Analytic Hierarchy Process (AHP). Journal of Geographic Information System, 12, 470-495. https://doi.org/10.4236/jgis.2020.125028

Received: September 12, 2020

Accepted: October 18, 2020

Published: October 21, 2020

Copyright ( 2020 by author(s) and Scientific Research Publishing Inc. This work is licensed under the Creative Commons Attribution International License (CC BY 4.0).

http://creativecommons.org/licenses/by/4.0/ (c) (i) Open Access

\begin{abstract}
Brazil has a predominantly renewable energy matrix, with large participation of water resource in domestic supply of energy. Data from 2019 National Energy Balance show that renewable sources (water, biomass, wind and solar photovoltaic) together represented $83 \%$ of domestic electric supply in 2018, where the remaining percentage (16.7\%) represented non-renewable sources. The generation of electricity through thermal solar technology was not representative. However, it is known that Brazil presents high potential for the installation of solar thermal plants, especially in the Northeastern Region, where direct normal solar irradiation values are high. It is observed that the (high) costs of the projects associated to the absence of a specific incentive program make Concentrating Solar Power (CSP) plants installation more and more time consuming. As a way to contribute to the insertion of solar thermal energy in Brazil, this article presents a methodology for the location of parabolic trough solar thermal plants of $80 \mathrm{MW}$ for the State of Bahia, located in the Northeastern Region of Brazil. Such methodology was based on the application the Analytic Hierarchy Process (AHP) method and the Geoprocessing Technologies to define potentially available sites for the implementation of the projects. For the analysis, parameters related to energy production in the solar power plant, electric, roadways and water infrastructure of the plant were taken into account, as well as the occupation, slopes and land use. Considering the analyses performed, it was confirmed that Bahia disposes of many sites with great generation potential, especially in the western region of the State (at Barreiras), where favorable conditions were found for the development of the technology. Localities situated in other region of the State were also confirmed as suitable, however with less site availability for the insertion of plants. Methodology validations were also carried out and indicated that the model reached the proposed objective, faithfully representing the real-world
\end{abstract}


simplifications that were made.

\section{Keywords}

Solar Energy, Location Studies, Solar Thermal Power Plants, Geoprocessing

\section{Introduction}

Currently, it is observed that solar thermal technology for the generation of electricity in Brazil is still incipient, without representation in the national energy matrix. Data from the 2019 National Energy Balance show that renewable sources (water, biomass, wind and solar photovoltaic) together represented $83 \%$ of domestic electric supply in 2018, where the remaining percentage $(16.7 \%)$ represented non-renewable sources. The generation of electricity through the use of solar thermal technology was not representative. However, it is known that Brazil presents high potential for the installation of solar thermal plants, especially in the Northeastern Region, where several researches were carried out and demonstrated the potential for the solar thermal technology (as shown in the works of [1] [2] [3] [4] [5]). It is observed that the (high) costs of the projects associated with the absence of a specific incentive program make Concentrating Solar Power (CSP) plants installation more and more time consuming. Based on these findings and aiming to contribute to the insertion of solar thermal energy in Brazil, this article presents a methodology for the location of parabolic trough solar thermal plants of $80 \mathrm{MW}$ for the State of Bahia (Northeastern Region of Brazil) based on the combined use of AHP Method and Geoprocessing Technologies. This combination (AHP + Geoprocessing Technologies) has already been carried out for potential sites definition by several authors in various regions of the world, as shown in the works of [6] [7] [8] [9] [10]. In general, AHP method has wide applicability in the analysis of complex decision problems, where doubt situations or information conflicts are present, such as the case of location studies. Using this method, the location problem can be structured in hierarchical levels, as the AHP method axioms assume, in order to facilitate its understanding and the search for solutions that, in our case, are the definition of suitability levels of a site for the insertion of CSP plants. The establishment of these levels of suitability necessarily passes through the firm analysis of scenarios generated and the use of Geographic Information System (GIS). The scenarios are responsible for the evaluation of problem hierarchies and definition of the weights of the variables considered important to the location of the solar power plant. In contrast, GIS is responsible for the geographic representation of these variables (which must be as close to reality as possible), its aggregation and geographic scenarios construction to make the decision making more agile. Therefore, the combined use of AHP and GIS for the location of solar power plants subsidizes the project implementation proposal. 


\section{Solar Thermal Plant Location Study: The Combined Use of AHP Method and Geoprocessing Technologies to Support the Definition of Potential Sites}

\subsection{The AHP Method}

The Analytic Hierarchy Process, or simply AHP Method, is one of the main methods of Multicriteria Decision Analysis (MDA). This method was developed by Thomas L. Saaty, in the mid-1980s, in order to obtain a general measurement theory to be used in the measurement of events in both physical and psychological domain.

The first step for the application of AHP method is to define the objective of the problem. According to [11], the objective of the method (or the problem to be solved) is a function to be developed and which structures the entire construction of the model. The objective can, in fact, define the decision rule to be used.

Once the objective is defined, the next step is the definition of the criteria and sub-criteria of the problem. The criteria allow the characterization of the main elements of a decision-making process and can be decomposed into sub-criteria. The sub-criteria, in turn, can be determined by indicators that have the function of defining its magnitudes. The indicators are classified as positive when they do not restrict the potential of an alternative; and as negative (or restrictions) when they restrict the alternatives due to the activity to be developed [11].

After the objective definition and the construction of hierarchies, a paired comparison of the criteria is performed. To make this comparison [12] proposed the use of a measurement scale aiming for the standardization of judgments, which is presented in Table 1.

From the use of Saaty's Scale, the criteria are compared among themselves, originating a matrix of criteria comparison (Figure 1), that is, the elements $a_{i j}$ of this matrix represent the judgment given to each pair of evaluated criteria.

With the criteria comparison matrix defined, the standardization of its elements is made to estimate the weights of the criteria $\left(w_{j}\right)$. One of the most used methods for this estimation is the Average of Normalized Columns, in which are performed the sum of the elements of each column of the Matrix $\left(S_{1}, S_{2}, \ldots S_{n}\right)$ to give rise to a new matrix, where each element is the result of the division of each element $a_{i j}$ of the matrix A by the sum of the corresponding column. As a last step of this procedure, the average of the normalized values of the rows is calculated, which corresponds to the values of the estimated weights.

After the definition of the criteria weights (global priority), the evaluation of the consistency of the model must be made in order to analyze the transitivity of the judged values. Such evaluation is made from the Consistency Ration (CR) which is calculated by Equations (1) and (2):

$$
\mathrm{CR}=\frac{\mathrm{CI}}{\mathrm{RI}}
$$




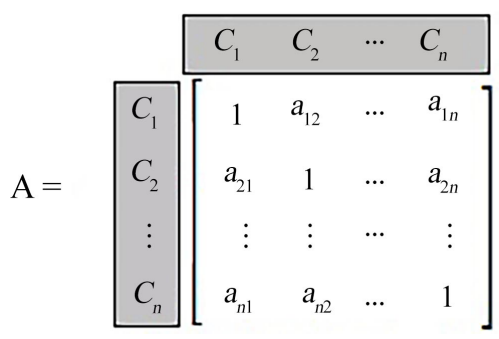

Figure 1. Criteria comparison Matrix A.

Table 1. Saaty's fundamental scale.

\begin{tabular}{cc}
\hline Intensity of Importance & Definition \\
\hline 1 & Equal Importance \\
3 & Weak Importance \\
5 & Moderate Importance \\
7 & Very Strong of Importance \\
9 & Extreme Importance \\
\hline
\end{tabular}

a. The inferior and superior limits of Saaty's Fundamental Scale are represented by 1 and 9, respectively, since psychological experiments demonstrate that the human being is not capable of comparing simultaneously more than objects. Also on this scale, even numeric values are left to intermediate values between the elements of the main scale [13].

$$
\mathrm{CI}=\frac{\lambda_{\text {max }}-n}{n-1}
$$

where: $\mathrm{CI}=$ consistency index of judgments; RI = random consistency index; $\lambda_{\max }=$ higher eigenvalue; and $n=$ matrix order.

This random consistency index, parameter of Equation (1), was empirically determined considering a sample of 500 positive reciprocal matrices, randomly generated [11]. The values attributed to RI by [12], according to the matrix order $(n)$, are shown in Table 2.

If the value found for the CR is greater or equal to 0.1 , the judgment values in the criteria comparison matrix should be revised, as they are not sufficiently consistent to estimate the weights $\left(w_{j}\right)$. In contrast, if such value is less than 0.1 , the judged values are considered satisfactory [12].

Once the judged values are defined as consistent (global priority), the whole process of obtaining priorities should be repeated for the sub-criteria in order to establish its order of importance for the solution of the proposed problem. Also for these, the consistency analysis of the judged values should be carried out [11].

\subsection{Geoprocessing Technologies Used in the Location Study in the State of Bahia}

The term Geoprocessing emerged to group in a single name the several existing technologies that use geographic information. Among these technologies are included the GIS, Global Positioning Systems (GPS), Remote sensing, Geodesy, 
Table 2. Empirical values of the random consistency index.

\begin{tabular}{cc}
\hline Matrix Order (n) & RI \\
\hline 2 & 0.00 \\
3 & 0.58 \\
4 & 0.90 \\
5 & 1.12 \\
6 & 1.24 \\
7 & 1.32 \\
8 & 1.41 \\
9 & 1.45 \\
10 & 1.49 \\
\hline
\end{tabular}

Photogrammetry, Topography and other cartographic and geographic techniques. To meet the objective of this research study, the used technologies were GIS, Map Algebra and Fuzzy Logic.

\subsubsection{GIS}

According to [14] GIS are computational systems developed for the purpose of digital processing of geographic information, considering its geometric, topologic and temporal aspects. They are composed by software resources developed to optimize the acquisition of geographic data, research and spatial analysis of geographic phenomena and facts, in addition to generating maps, letters, digital plants or various reports, achieving integration of geographic information at various thematic levels. In a social and technological perspective, the GIS is, in general, associated with institutional projects and requires qualified personnel for its operation, composing multidisciplinary work teams, with diverse and specific purposes.

In general, GIS may be represented as a network that links people to spatial data, through the use of hardware, software and procedure [15]. The software corresponds to computational programs used in GIS; The hardware corresponds to the computational platform used; The data comprise the geographic information that forms the Spatial Database (SD) of the system; The people represent the professionals responsible for the project, as well as system users. The procedures comprise the methodologies and the existent practical actions for the system to operate properly for the organization. For more details, see [15].

\subsubsection{Map Algebra}

A cartographic technique highly used in location studies is the Map Algebra. Map Algebra (or Field Algebra) was introduced by Dana Tomlin in the late 1970s and can be seen as a set of conventions, analytical skills and techniques to perform operations with geographical fields in the matrix model in GIS environment. 
The operators of the Map Algebra treat the geographical fields as individual variables, layers, associating each geographic position of a determined study site to a qualitative or quantitative value, using expressions with well-defined syntax. For more details, see [16] [17].

\subsubsection{Fuzzy Logic}

In location studies based on GIS and MDA, an important step is the normalization of spatial data. The normalization has the purpose of representing the spatial data values (originally not comparable to each other) in a continuous scale to allow the aggregation between them in the GIS environment. One of the most used techniques for normalization is fuzzy logic.

Fuzzy logic is based on the fuzzy sets theory, which represents classes of elements that do not have well defined frontiers [18]. The use of fuzzy sets is based on inference rules and is indicated for situations dealing with ambiguity, abstraction and ambivalence in mathematical or conceptual models of empirical phenomena [19]. Fuzzy membership functions represent the semantic properties of fuzzy sets and can present distinct formats (such as linear, triangular, trapezoidal, gaussian and sigmoidal functions). Greater details can be seen in [19] [20] [21].

\section{Materials and Methods}

\subsection{Material Used}

The materials used to carry out this research were: 1) Spring 5.2.6 (INPE) and QGIS 3.2.1 software; 2) Shapefiles; 3) SRTM mission data and 4) Landsat 8 satellite images.

\subsection{Study Area Identification}

Bahia is located in the Northeastern Region of Brazil and has a territorial area of $564,760.427 \mathrm{~km}^{2}$. The State borders with the Atlantic Ocean and with the States of Espírito Santo, Minas Gerais, Goiás, Tocantins, Piauí, Pernambuco, Alagoas and Sergipe.

Considering the Regional Division of Brazil into Intermediate Geographic Regions (IGR), Bahia has ten environments as show in Figure 2 Intermediate Geographic Regions Map of the State of Bahia: Salvador, Santo Antônio de Jesus, Ilhéus-Itabuna, Vitória da Conquista, Guanambi, Barreiras, Irecê, Juazeiro, Paulo Afonso and Feira de Santana.

\subsection{Methodology}

The model used to approach the problem of solar thermal plants location in the State of Bahia was the AHP method. This method was chosen because, in addition to aggregating different criteria in a single function (which will be optimized), it has easy implementation and simple algorithm presentation. The stages of model elaboration are presented in Figure 3. 


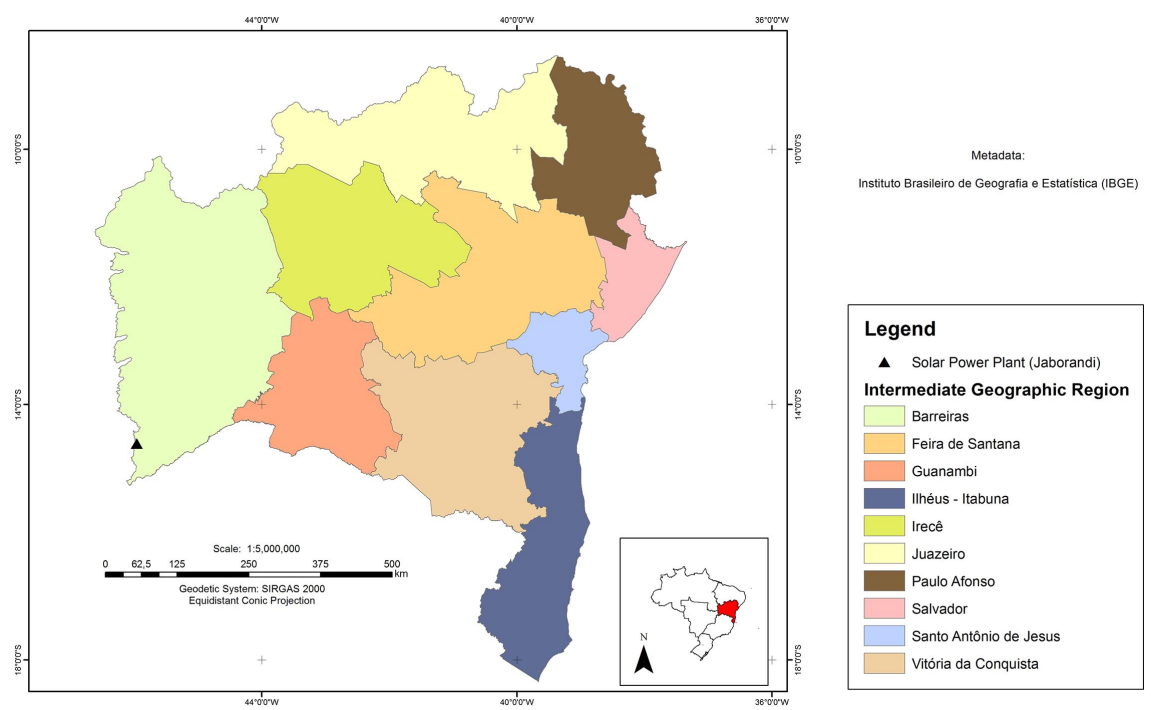

Figure 2. Bahia by intermediate geographic regions.

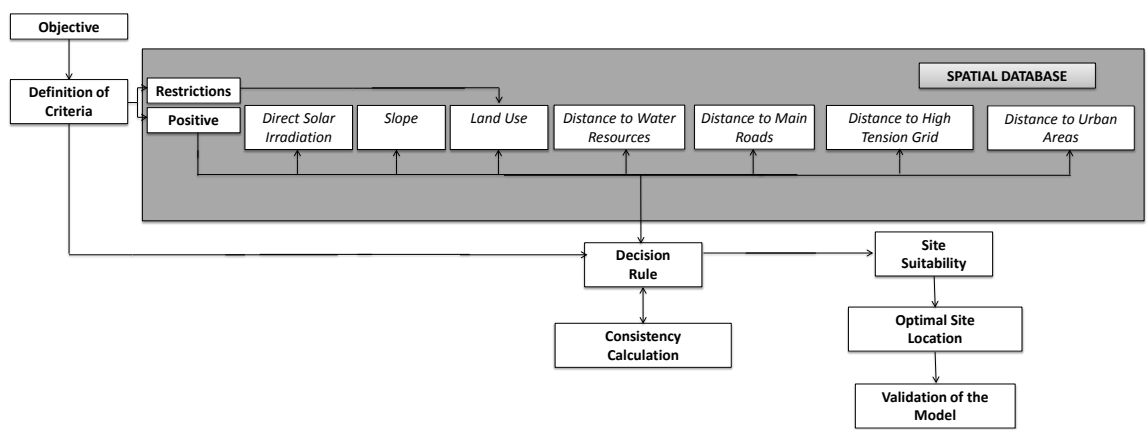

Figure 3. Methodological procedures performed for the location.

\subsubsection{Definition of the Criteria}

To evaluate the problem of solar thermal plants location in the State of Bahia, four criteria were defined: Climate, which defines the production of electricity generated in the solar power plant; Topographic, which takes into consideration the aspects related to land preparation for the installation of the solar power plant; Environmental, which considers site suitability for the insertion of solar power plants; and Location, which considers the main roads, water and power lines interconnections to the solar power plants, as well as the proximity of the solar power plant to urban and urban expansion areas. These criteria were established based on several solar power plants location studies carried out throughout the world, which gather the MDA and GIS concepts for the identification of sites suitable for installation. Still, to facilitate the application in this study, the criteria were subdivided into sub-criteria, thus characterizing the positive indicators (Table 3 ) and restrictions (Table 4).

- Positive Indicators

According to Table 3, positive indicators refer to direct normal solar irradiation, slope, distance to power lines, distance to water resources, distance to main road, distance to urban areas and land use (except areas of high agricultural potential). 
Table 3. Positive indicators.

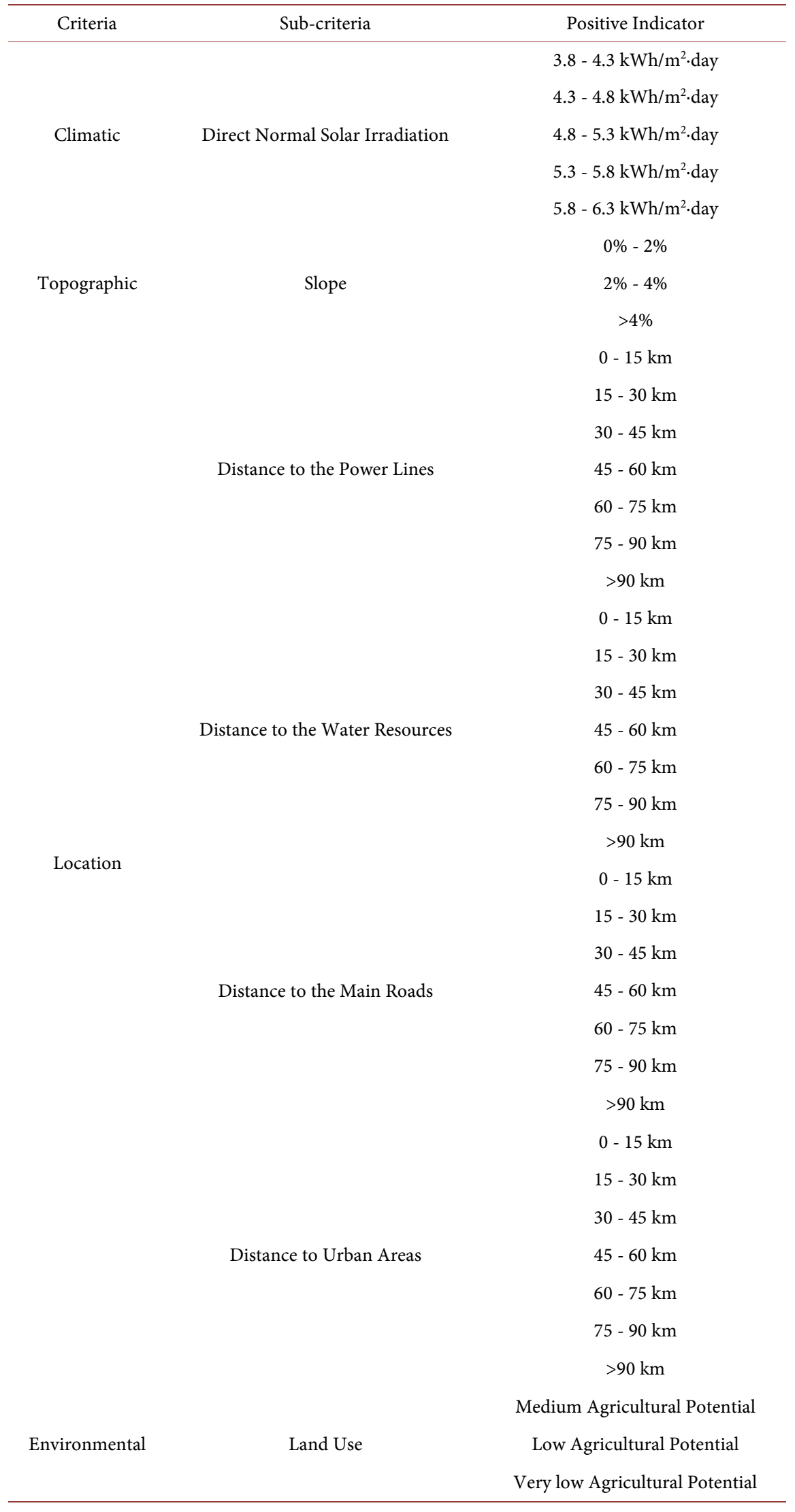


Table 4. Negative indicators or restrictions.

\begin{tabular}{ccc}
\hline Criteria & Sub-criteria & Restrictions \\
\hline & & Conservation Units \\
Environmental & Land Use & Remnants of the Atlantic Forest \\
& Indigenous Territories \\
& Quilombola Territories \\
& High Agricultural Potential \\
& Urban and Urban Expansion Areas \\
& Water Bodies \\
\hline
\end{tabular}

Direct normal solar irradiation is considered more important in the indication of potential sites for solar thermal plants installations, once it defines, quantitatively, the production of electricity of the solar power plant [22]. In fact, if we consider the flat-plate solar collector on the earth's surface tilted from a $\beta$ angle in relation to the horizontal, the total solar irradiation $\left(I_{h}\right)$ that reaches this plane at a given instant will be given by the sum of two components: direct and diffuse irradiation, such as shown in Equation (3) [5].

$$
I_{c}=I_{b n} \cos \theta+I_{d} \frac{\sin \beta}{\pi C}
$$

where: $I_{c}=$ solar irradiation on the surface of the collector; $I_{b n}=$ direct normal solar irradiation; $\theta=$ angle formed by the rays with the horizontal plane; $I_{d}=$ diffuse solar irradiation incident on the horizontal plane; $\beta=$ edge angle; $\pi=$ incidence angle; and $C=$ geometric concentration.

Solar thermal power plants that present a geometric concentration ratio considered high, defined in the range of $50<C<100$, for example, the diffuse contribution will reflect in a small fraction (negligible) of the solar irradiation incident on the surface of the collector, that is, the solar collector will see, practically, only the direct portion of solar irradiation incident on its surface $\left(I_{c}=I_{b n} \cos \theta\right)$. Therefore, the knowledge of direct normal solar irradiation in a given location is an essential factor for location studies.

The knowledge of land slope where the solar power plant will be installed is also an important factor for choosing the location, because it determines its impact on the costs for preparing and leveling the land. The ideal would be to have flat land, but with enough slope to allow the natural drainage of the land.

Regarding the distance to electric, water and road infrastructure elements, it is observed that the ideal is to have a proximity of the solar power plant with power lines, water resources and main roads in order to avoid increases to the total cost of the project in case of the necessity to build new pipelines or demand the expansion of power lines and existing road network to serve regions favorable to the implementation of the projects.

For urban and urban expansion areas, the issue of proximity is also a very important factor. For those, however, the ideal is that the solar power plant has a considerable distance from these regions, since both urban and urban expansion areas must be preserving in order to fulfill their social function (housing, work, 
recreation, circulation, among others).

Finally, with regard to land use, it is observed that the sites not used to productive purposes are more indicated for the installation of solar power plants. In this research, the sites considered as positive aspect in the model were those classified as: medium to high agricultural potential. On the other hand, the areas with high agricultural potential were considered as negative aspect in the model.

The thematic maps presented in Figures 4-10 show the spatial distribution of positive indicators in the studied area. Important to note that all these Maps were georeferenced to the Geodetic Reference System SIRGAS2000, which represents the official geodetic reference system for the Brazilian Geodetic System (BGS) and for the National Cartographic System (NCS). The Coordinate System used was the Geodetic Coordinate System (Latitude and Longitude) and the Cartographic Projection used was the Equidistant Conic.
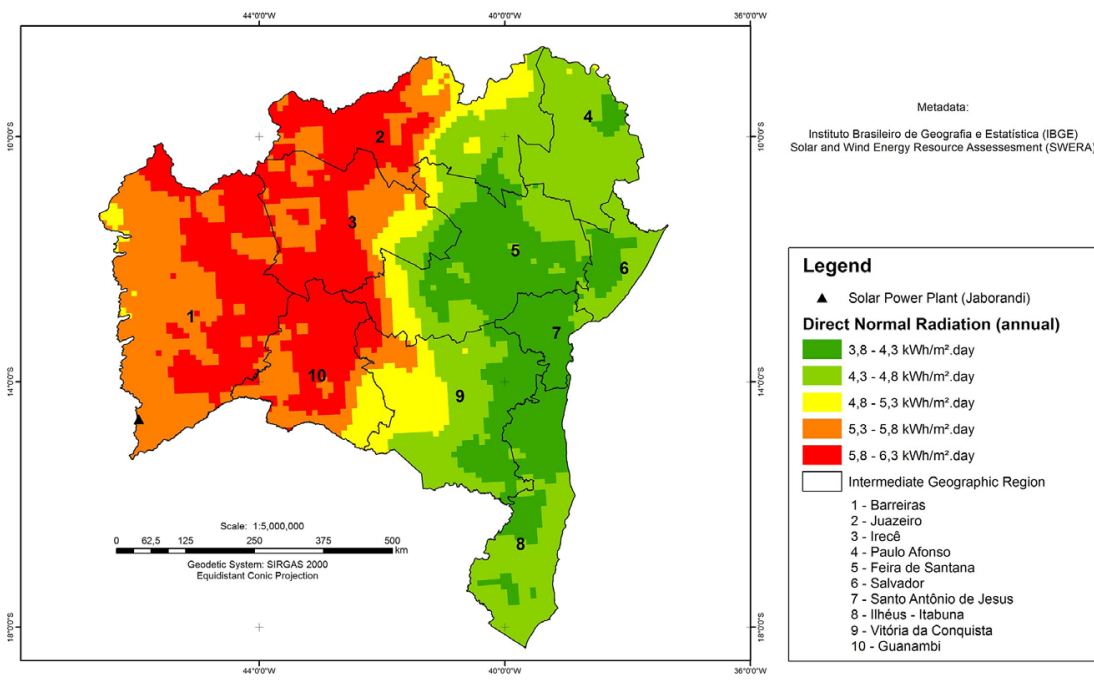

Figure 4. Direct normal solar irradiation map (annual average daily values) for the State of Bahia.
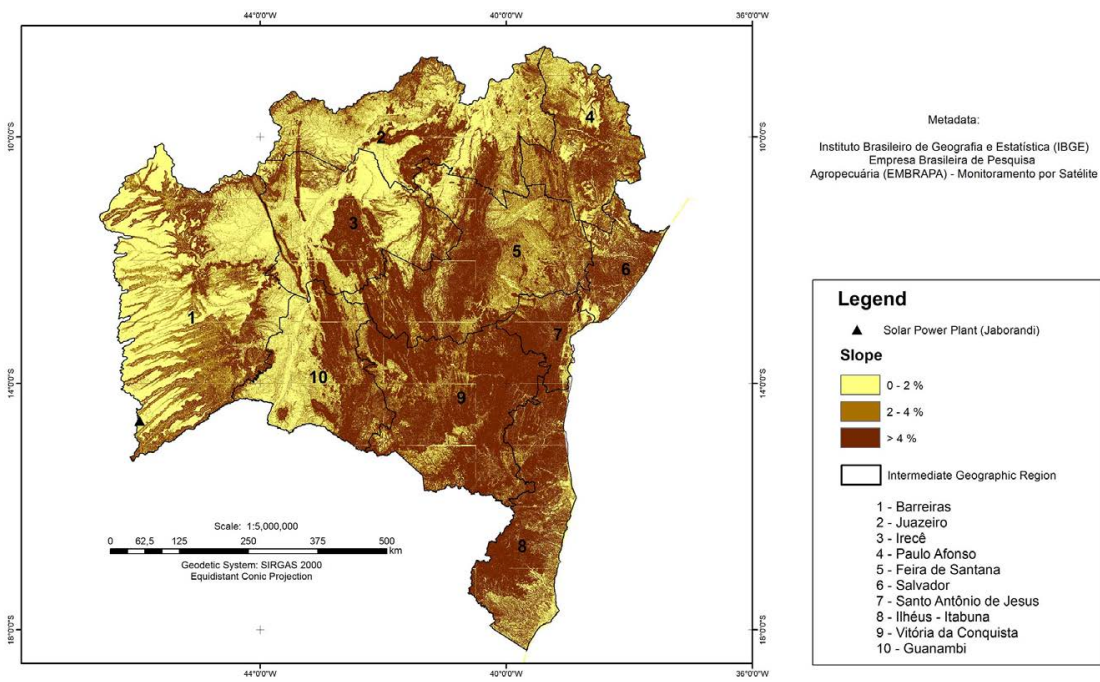

Figure 5. Slope map for the state of bahia. 


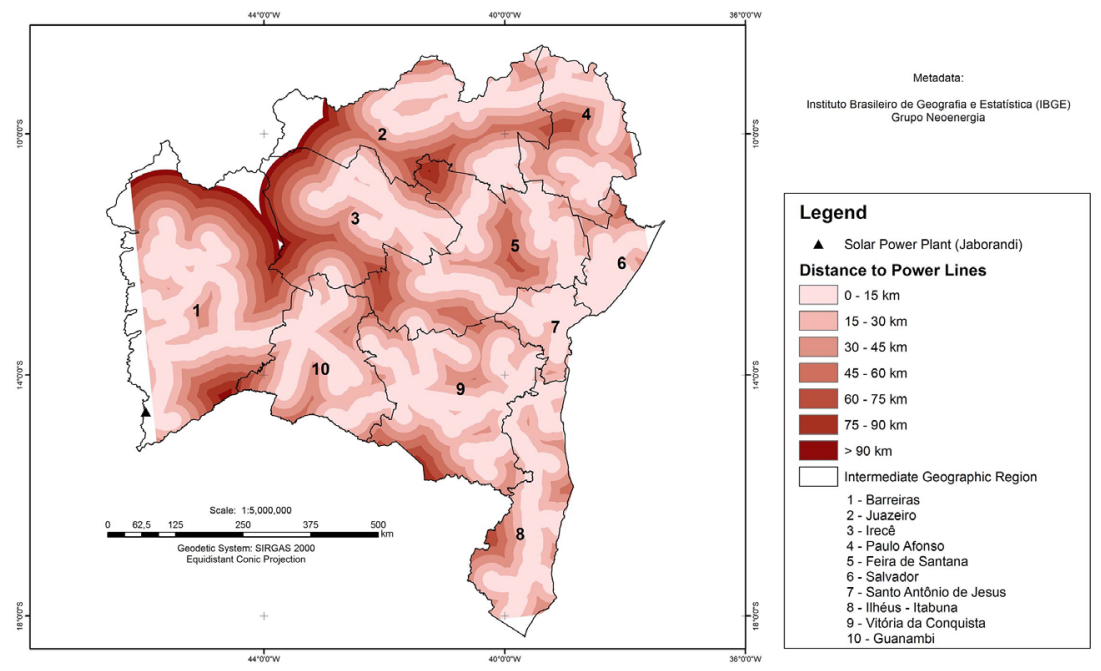

Figure 6. Map of distances to power lines for the State of Bahia.
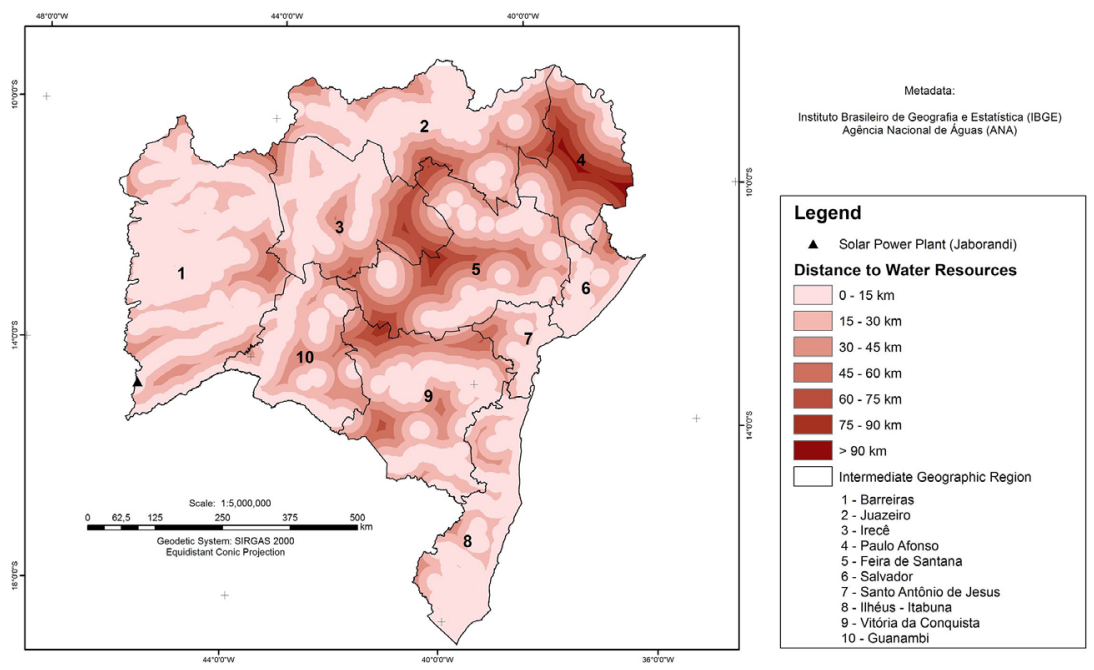

Figure 7. Map of distances to waters resources for the State of Bahia.

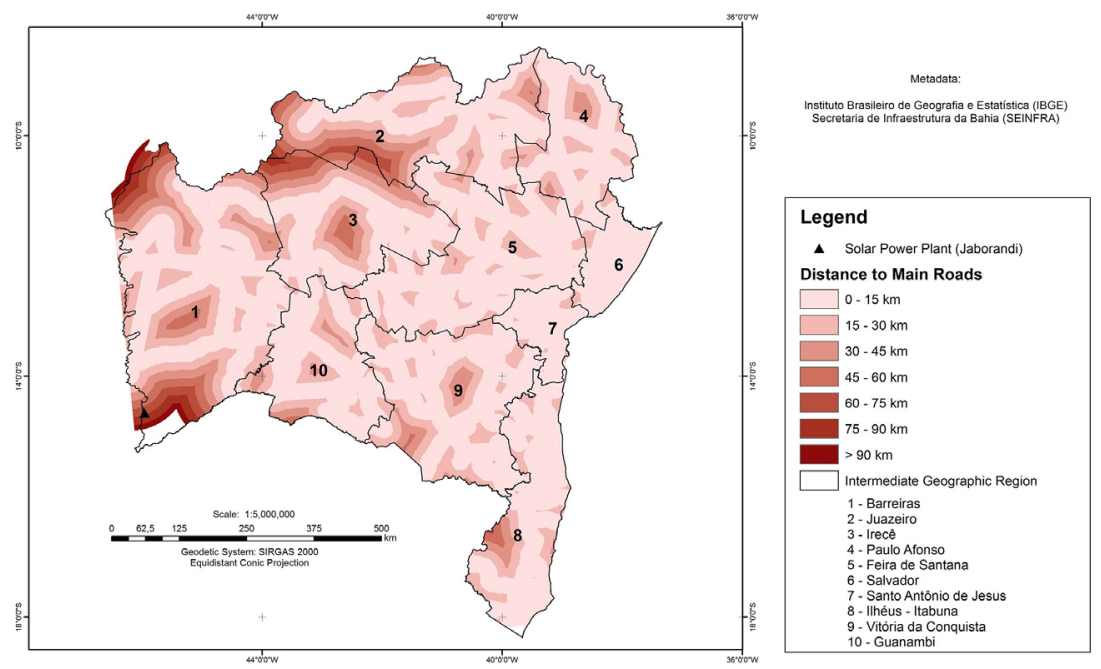

Figure 8. Map of distances to main roads for the State of Bahia. 

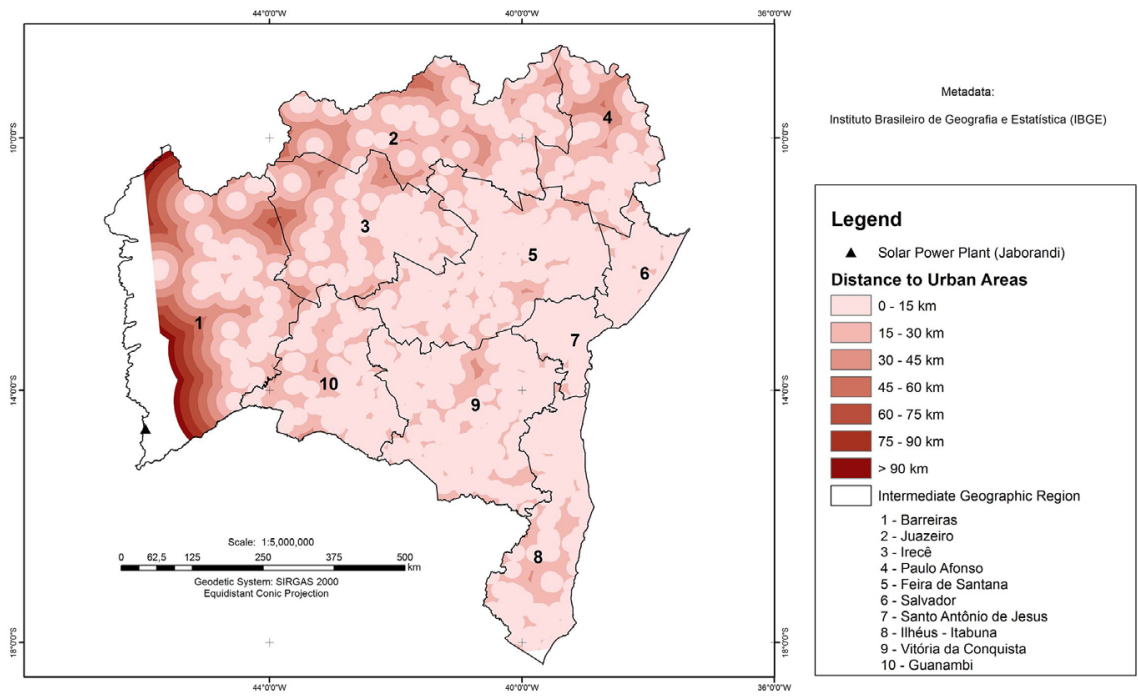

Figure 9. Map of distances to urban areas for the State of Bahia.
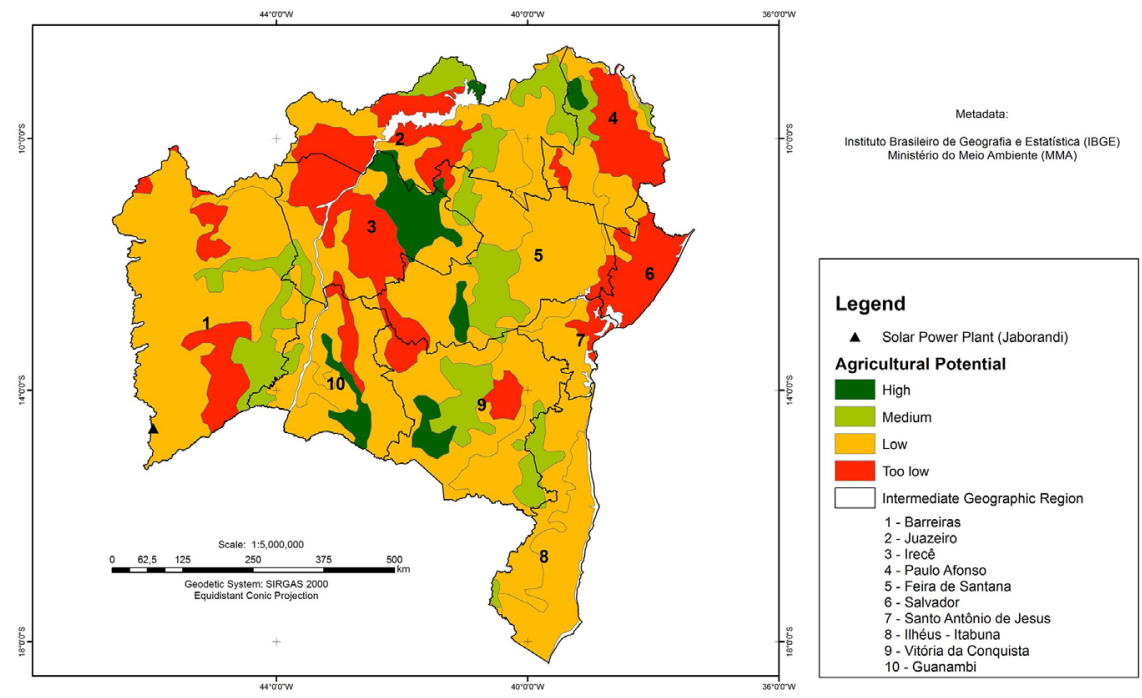

Figure 10. Agricultural potential map for the State of Bahia.

As can be seen in Figure 4, the direct normal solar irradiation indexes in Bahia range from 3.8 to $6.3 \mathrm{kWh} / \mathrm{m}^{2}$.day (annual average). The higher values were located, mostly, in Intermediate Geographic Regions of Barreiras, Juazeiro, Irecê and Guanambi. On the other hand, lower values (between 3.8 to $4.3 \mathrm{kWh} / \mathrm{m}^{2}$.day) were predominantly in the Intermediate Geographic Regions of Feira de Santana, Salvador, Santo Antônio de Jesus, Ilhéus-Itabuna and Vitória da Conquista. At the location of Jaborandi Solar Power Plant, direct normal solar irradiation is of the order of 5.3 to $5.8 \mathrm{kWh} / \mathrm{m}^{2}$.day (annual average), which are values considered very good for the installation of CSP projects.

According to the Map in Figure 5, it is observed that the highest slope percentages (higher than $4 \%$ ) were mostly located in the Intermediate Geographic Regions of Feira de Santana, Salvador, Santo Antônio de Jesus, Vitória da Conquista and Ilhéus-Itabuna. Higher percentages can also be found in parts of In- 
termediate Geographic Regions of Guanambi, Irecê and Juazeiro. On the other hand, gentler slopes $(0 \%-2 \%, 2 \%-4 \%)$ are located in the Intermediate Geographic Regions of Barreiras, Juazeiro, Irecê, Guanambi and Paulo Afonso. The land slope where Jaborandi Solar Power Plant is in the range of $0 \%-2 \%$, which satisfies a great condition for project installation, once several authors [22] [23], indicate that maximum land slope for project installation should not be higher than $5 \%$.

From the Map in Figure 6, it is verified that greater distances to power lines are located in the west of the State, especially in Intermediate Geographic Regions of Barreiras, Juazeiro and Irecê. In the neighboring area of Intermediate Geographic Regions of Juazeiro and Feira de Santana are also found large distances (above $60 \mathrm{~km}$ ) between power lines. The region of Jaborandi Solar Power Plant is not contemplated by the Map, however, if an extension of the model is made for its region, it can be said that Jaborandi Solar Power Plant is located in a region of small distance to the power lines of $138 \mathrm{kV}(0-15 \mathrm{~km})$, what also highlights a great criteria for the installation of CSP projects.

In the Map in Figure 7, it is observed that the greater distances to water resources in the State of Bahia are mainly located in the central areas of Intermediate Geographic Region of Paulo Afonso and at the border between Intermediate Geographic Regions of Salvador and Feira de Santana. Sill in this Map, it can be verified that Jaborandi Solar Power Plant is located in a region of small distance to permanent water resources $(0-15 \mathrm{~km})$, which also shows a great criteria for the installation of CSP projects.

According to the Map shown in Figure 8, it is observed that greater distances to main roads are located in the Intermediate Geographic Region of Barreiras, in the extreme west of the State, and at the border between Intermediate Geographic Regions of Juazeiro and Irecê. In it, it is also observed that Jaborandi Solar Power Plant is located in a region of distances of $60-75 \mathrm{~km}$ to the main roads (state and federal), which suggests that the access to the plant should be made by municipal roads or private roads in the region.

Regarding the Map in Figure 9, it is verified that the larger concentration of urban areas is located in the eastern portion of the State, mostly in the Intermediate Geographic Region of Salvador, and the greater distances to urban areas (above $60 \mathrm{~km}$ ) are located in the extreme west of the State, in the Intermediate Geographic Region of Barreiras. In this respect, it is seen that Jaborandi Solar Power Plant is located in a region of great distances to the main urban centers of the State, which is also considered a great criteria for the installation of CSP projects.

Lastly, considering the Map in Figure 10, it is verified that the State has many sites with low or very low agricultural potential. On the other hand, high potential areas can be found in Intermediate Geographical Regions of Irecê, Guanambi, Paulo Afonso, Feira de Santana and Vitória da Conquista. In this regard, it is verified that Jaborandi Solar Power Plant is situated in a low agricultural potential area, which makes it propitious for the installation of CSP projects, once the 
site is not used for productive purposes.

\section{- Restrictions}

The restrictions are related to those sites which activity or occupation must be preserved and controlled. In this study, the environments incorporated as restrictions are the following: Federal Conservation Units for Sustainable Use and Comprehensive Protection, Atlantic Forest Remnants; Indigenous Territories; Quilombola Territories; High Agricultural Potential Areas; Urban Areas; and Water Bodies, as illustrated in Figure 11.

From the Map presented in Figure 11, it is observed that there is a greater concentration of restriction areas in the southeastern and central portions of the State of Bahia.

Considering the sites occupied by Federal Conservation Units (FCU), it is verified that the State has a total of 24 FCU. With regard to Atlantic Forest Remnants, these occupy an area of $75,481.57 \mathrm{~km}^{2}$, approximately, according to the data from SOSMA Foundation (SOS Mata Atlântica Foundation). Such remnants are situated in the Intermediate Geographic Regions of Salvador, Santo Antônio de Jesus, Vitória da Conquista and Ilhéus-Itabuna.

In Bahia, there are currently 15 Indigenous Territories according to FUNAI (National Indian Foundation), which are located in the Intermediate Geographic Regions of Irecê, Guanambi, Paulo Afonso, Santo Antônio de Jesus and Ilhéus-Itabuna. The Quilombola Territories (around 36 communities) are found in all Intermediate Geographic Regions of the State.

High agricultural potential areas are found in Intermediate Geographic Regions of Irecê, Guanambi, Paulo Afonso, Feira de Santana and Vitória da Conquista. Finally, the sites with larger concentration of water bodies in the territory are situated, mostly, in the eastern and western potions of the State, where the Intermediate Geographic Regions of Barreiras, Juazeiro, Irecê (western portion) and Salvador, Santo Antônio de Jesus, Ilhéus-Itabuna and Vitória da Conquista (eastern portion) are located.
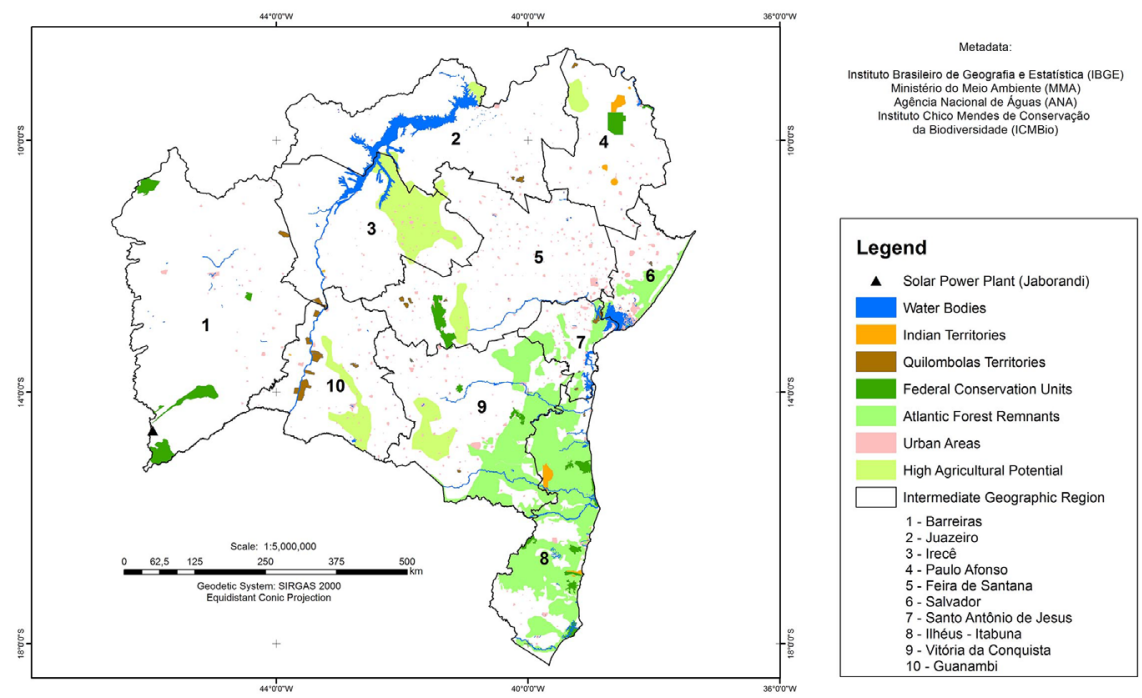

Figure 11. Map of restriction areas for the State of Bahia. 
Jaborandi Solar Power Plant is located in a region where no restrictions regarding land use are observed. This makes it suitable for the installation of CSP projects.

\subsubsection{Decision Rule Definition}

To evaluate the solar thermal power plant location problem in the State of Bahia, a Decision Rule was established for each one of the three scenarios developed for this study. In the first scenario, for example, the Climatic criteria was considered as most important for the decision rule. Following in order of importance, the Topographic, Environmental and Location criteria were defined, as shown in Figure 12.

A scenario without weights-Starting Point Scenario-was also generated to define the sites suitable for installation from the use of all indicators of the study (positive and restrictions), without considering the weights. It was also competed to this scenario to serve as reference to analyze the influence of weighting in the final result of each scenario created.

\subsubsection{Weight Estimation and Model Consistency Calculation}

After the establishment of the Decision Rule, the Weight Estimation for the problem criteria was carried out. Therefore, a paired comparison was performed between the pairs of criteria, using Saaty's Fundamental Scale, which gave rise to the Pairwise Comparison Matrix (Matrix A). This matrix was, then, normalized using the Average of Normalized Columns method to estimate the priority vectors $\left(w_{j}\right)$. The step by step of this determination, for Scenario 1, is shown below:

In Scenario 1, the Decision Rule adopted in order of importance was the sequence Climatic $\rightarrow$ Topographic $\rightarrow$ Environmental $\rightarrow$ Location, and then the pairwise comparison matrix had its format presented in Table 5. The normalization of this matrix is presented in Table 6.

In Table 6 can be seen that the Climatic criteria presented higher weight (46\%) when compared to Topographic (29\%), Environmental (16\%) and Location (9\%).

Once obtained the priority vectors for the criteria, the Model Consistency Evaluation was carried out to verify transitivity of the judged values. The Consistency Ration calculation was made from the use of Equations (1) and (2) as well as the empirical value of Random Consistency Index equivalent to $n=4$ (matrix order), shown in Table 2. The values found for the greater eigenvalue, the consistency index of judgments and consistency ration were, respectively, $\lambda_{\max }=4.045870784, \mathrm{CI}=0.015290261$ and $\mathrm{CR}=0.016989179$. As the $\mathrm{CR}$ value was less than 0.10 (model request), the estimated values for the criteria were stated to be consistent.

With all the Scenario 1 criteria hierarchically organized, the entire process for obtaining the priorities vector and transitivity evaluation of the judged values was reproduced for the sub-criteria for the determination of final weights. Such final weights, as well as the $\lambda_{\max }, \mathrm{CI}$ and CR values calculated for the sub-criteria in Scenario 1, are presented in Table 7. 


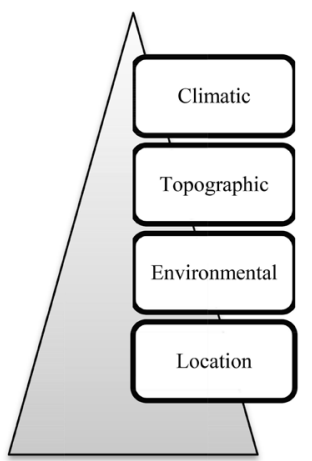

Scenario 1

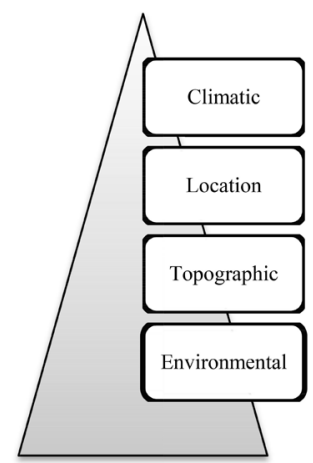

Scenario 2

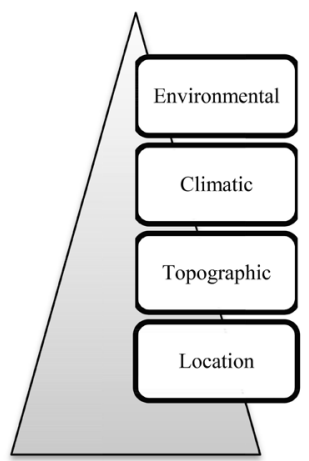

Scenario 3

Figure 12. Presentation of scenarios for the application of AHP method.

Table 5. Pairwise comparison criteria for scenario 1.

\begin{tabular}{ccccc}
\hline Criteria & Environmental & Topographic & Location & Climatic \\
\hline Environmental & 1.00 & 0.50 & 2.00 & 0.33 \\
Topographic & 2.00 & 1.00 & 4.00 & 0.50 \\
Location & 0.50 & 0.25 & 1.00 & 0.25 \\
Climatic & 3.00 & 2.00 & 4.00 & 1.00 \\
Sum & 6.50 & 3.75 & 11.00 & 2.08 \\
\hline
\end{tabular}

Table 6. Auxiliary matrix for the obtaining of the criteria weights-scenario 1 .

\begin{tabular}{cccccc}
\hline Criteria & Environmental & Topographic & Location & Climatic & Priority Vector (wj) \\
\hline Environmental & 0.1538 & 0.1333 & 0.1818 & 0.1600 & 0.1572 \\
Topographic & 0.3076 & 0.2667 & 0.3636 & 0.2400 & 0.2944 \\
Location & 0.0769 & 0.0667 & 0.0909 & 0.1200 & 0.0886 \\
Climatic & 0.4615 & 0.5330 & 0.3636 & 0.4800 & 0.4597 \\
\hline
\end{tabular}

Table 7. Final Weights and $\lambda_{\max }, \mathrm{CI}$ and CR for the Sub-criteria-Scenario 1.

\begin{tabular}{cccc}
\hline Sub-criteria (Weights) & $\lambda_{\max }$ & CI & CR \\
\hline Solar Irradiation (42.255\%) & & \\
Slope (25.702\%) & & \\
Land Use (17.969\%) & & \\
Power Lines Dist. (5.270\%) & & 0.02087315812998 \\
Water Resources Dist. (3.640\%) & & \\
Main Road Dist. (2.893\%) & & \\
Urban Area Dist. (2.271\%)
\end{tabular}

As the CR value was less than 0.10 (Table 7), the values judged for the sub-criteria were also stated as consistent.

In a similar way, the criteria and sub-criteria weights estimation were performed for Scenario 2 and 3, as well as the model consistency calculation. The 
weights estimation and the values found of $\lambda_{\max }, \mathrm{CI}$ and CR for the sub-criteria of Scenarios 2 and 3 are presented, respectively, in Table 8 and Table 9.

As the CR value was less than 0.10 in Table 8 and Table 9, the estimated values for the sub-criteria were also stated as consistent.

\section{Results and Discussion}

\subsection{Presentation of the Scenarios}

To identify the suitable sites for the installation of solar power plants in the State of Bahia, the WLC (Weighted Linear Combination) technique was used. The WLC technique combines different layers, with their respective weights, to generate final suitability maps. In the case of solar power plants location studies, it can be said that it combines all the indicators of the study (negative and positive), with their respective weights, to create a continuous suitability classification of the areas in the region of interest, as shown in Equation (4):

$$
I=\sum_{i=1}^{n} w_{i} x_{i} \cdot \prod_{j=1}^{k} c_{j}
$$

where: $I=$ final value of the score; $n=$ number of positive indicators; $w_{i}=$ weight of positive indicator $i ; x_{i}=$ normalized value of positive indicator $i ; k=$ number of exclusion criteria; and $c_{j}=$ score $(0$ or 1$)$ of the exclusion criteria.

Table 8. Final Weights and $\lambda_{\max }$, CI and CR for the Sub-criteria-Scenario 2.

\begin{tabular}{cccc}
\hline Sub-criteria (Weights) & $\lambda_{\max }$ & CI & CR \\
\hline Solar Irradiation (46.999\%) & & & \\
Power Lines Dist. (14.620\%) & & & \\
Water Resources Dist. (12.885\%) & & & \\
Main Road Dist. (10.393\%) & 7.11841258 & 0.019735431 & 0.0149510842 \\
Urban Areas Dist. (8.807\%) & & & \\
Slope (3.927\%) & & & \\
Land Use (2.369\%) & & &
\end{tabular}

Table 9. Final Weights and $\lambda_{\max }, \mathrm{CI}$ and CR for the Sub-criteria-Scenario 3.

\begin{tabular}{|c|c|c|c|}
\hline Sub-criteria (Weights) & $\lambda_{\max }$ & CI & $\mathrm{CR}$ \\
\hline \multicolumn{4}{|l|}{ Lande Use (40.671\%) } \\
\hline \multicolumn{4}{|l|}{ Solar Irradiation (22.406\%) } \\
\hline \multicolumn{4}{|l|}{ Slope $(18.916 \%)$} \\
\hline Power Lines Dist. (6.543\%) & 7.056814489 & 0.009469081 & 0.007173547 \\
\hline \multicolumn{4}{|l|}{ Water Resources Dist. (5.190\%) } \\
\hline \multicolumn{4}{|l|}{ Main Road Dist. (3.617\%) } \\
\hline Urban Areas Dist. (2.658\%) & & & \\
\hline
\end{tabular}


To normalize the positive indicators, the sigmoidal fuzzy membership function was used, because, according to [21], the use of this function associated to a set of control points allows to properly represent the period in which the effect of the normalized value for the final result is more effective. The format of the sigmoidal fuzzy membership function is shown in Figure 13.

Contrary to the positive indicators that determine continuous surfaces for suitable sites, the restrictions (or negative indicators) present well defined limits, segmenting the classification of the sites as suitable and not suitable for a desired end. That way, the restrictions present a boolean format (binary nature) with suitability analysis given by: value one (1) when there is site suitability; and otherwise, the value zero (0).

The results found for the Starting Point Scenario is shown in Figure 14.

From the Map in Figure 14, it is seen that the greater availability of high suitability sites for the installation of solar power plants in the Starting Point Scenario (class 7) are found in the western and northern regions of the State, especially in the Intermediate Geographic Regions (IGR) of Barreiras, Juazeiro, Irecê and Guanambi. On the other hand, the sites of less availability (classes 1,2 and 3) are found in all the IGR, especially in those located in the central and eastern portions of the State.

The sites located in the southern region of the State, in this Starting Point Scenario, did not present much availability for the installation of projects since the sites suitability found there are considered low (classes 1, 2 and 3). Important to note that, regardless the values associated with suitability classes, this region will show itself inadequate for the installation of projects because many of its sites are occupied by restriction areas. Such characteristic will also be present in other regions occupied by restriction areas.

As seen in the Map in Figure 15, the region of Jaborandi Solar Power Plant is not covered by the model. This occurs due to the absence of spatial information (and interpolated) of some layers in the region. However, considering the extension of the model for the region, it is safe to say that Jaborandi Solar Power Plant is located in an intermediate suitability site, where the values of the classes vary between 3 and 4 .

The results found for Scenario 1 are shown in Figure 15.

Looking at the Map in Figure 15 and comparing it to the Map in Figure 14, it can be seen that there are flagrant differences introduced by the consideration of the weights. The high suitability classes (class 7 and 6) are concentrated in western and northern regions of the State, however they cover a larger number of locations when compared to the Starting Point Scenario. The IGR where these locations are situated is the IGR of Barreiras, Juazeiro, Irecê and Guanambi.

Suitability classes considered low (classes 1,2 and 3) are predominantly in central and eastern regions of the State and cover, mainly, locations of the IGR of Paulo Afonso, Feira de Santana, Salvador, Santo Antônio de Jesus, Ilhéus-Itabuna and Vitória da Conquista. 


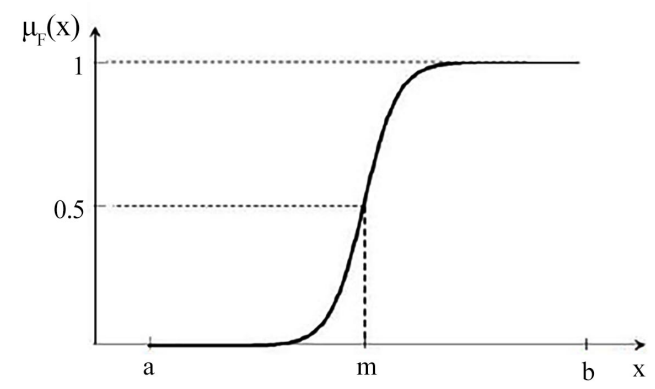

Figure 13. Sigmoidal fuzzy membership function.
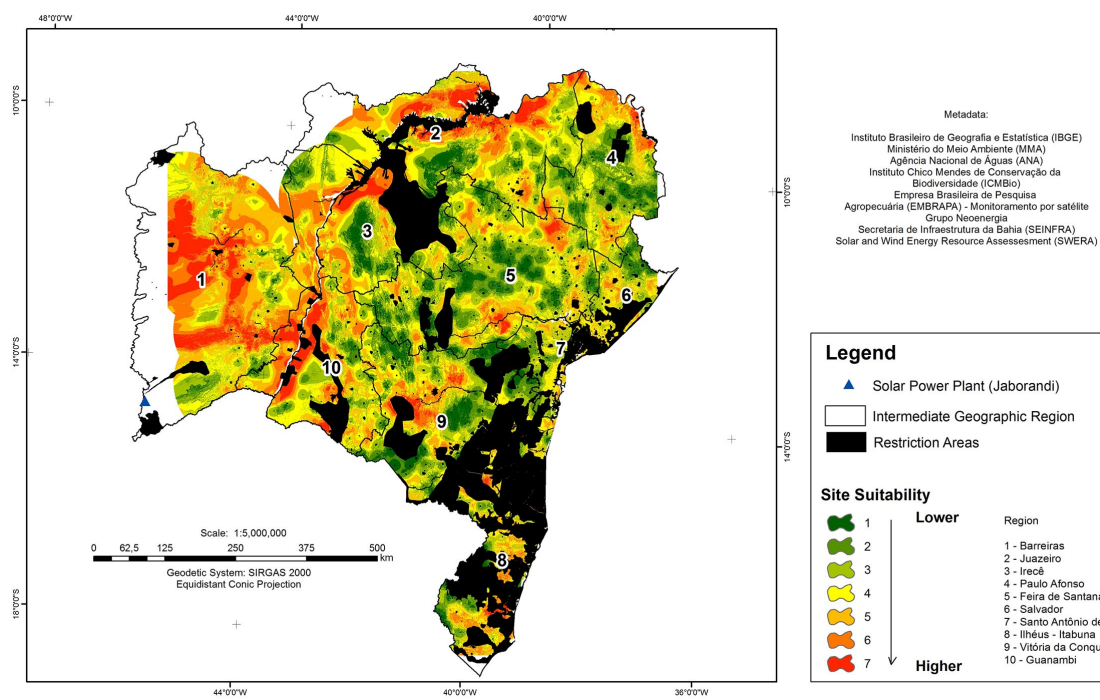

Figure 14. Map of Site Suitability—Starting Point Scenario.
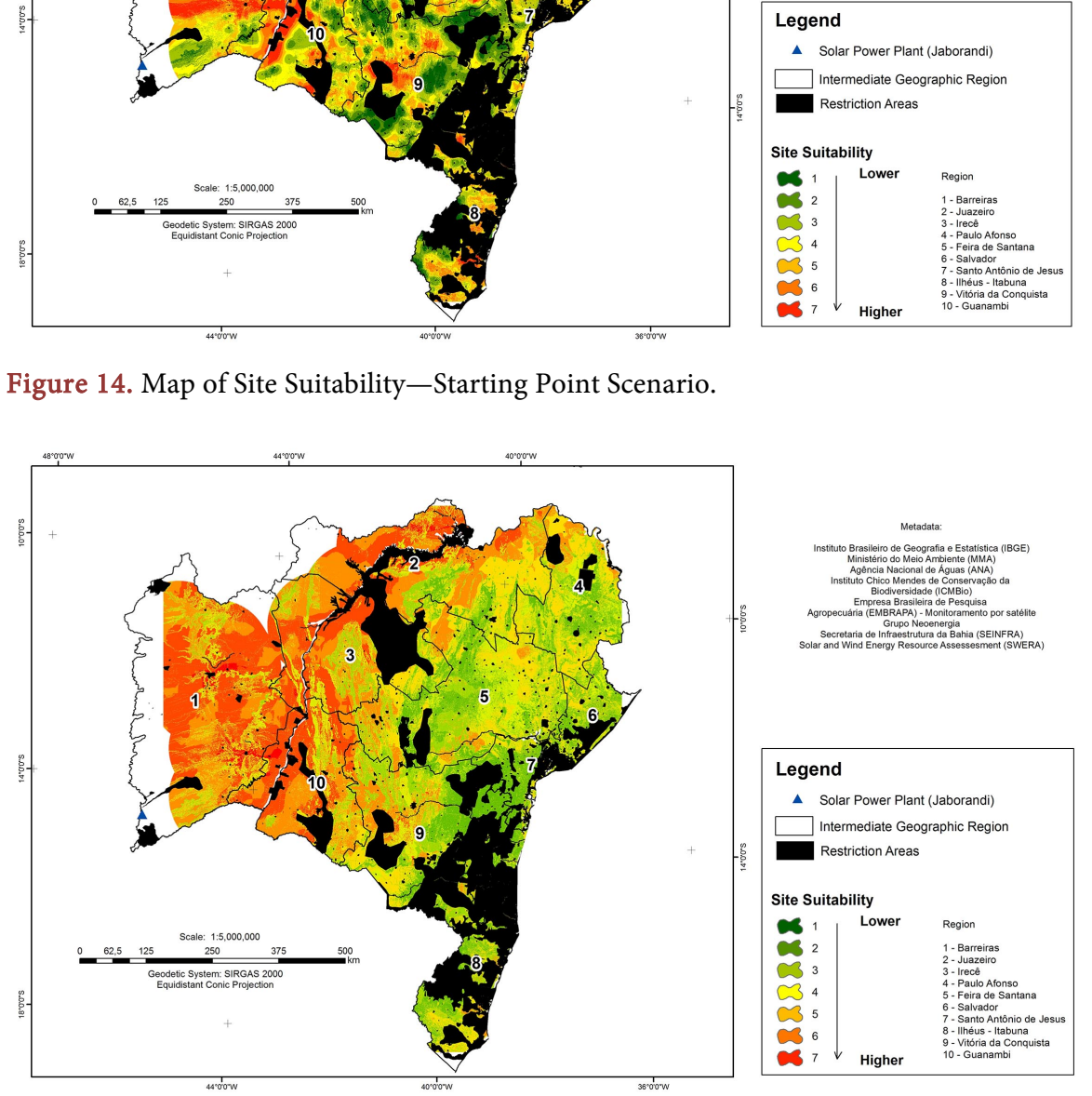

Figure 15. Map of Site Suitability—Scenario 1.

Again, considering an extension of the model for the region of Jaborandi Solar Power Plant, it can be said that the Plant is in intermediate suitability site, where the values of classes vary between 3 and 4 . 
The results found for Scenario 2 are shown in Figure 16.

Looking at the Map in Figure 16 and comparing it to the Map in Figure 14, it can be seen that high suitability sites (class 7) were enlarged and now concentrate in the eastern portion of the State, covering once more the IGR of Barreiras, Juazeiro, Irecê and Guanambi. In contrast, the classes of lower suitability (classes 1, 2 and 3) remained in the central and eastern regions of the State, covering, mostly, the locations in the IGR of Paulo Afonso, Feira de Santana, Salvador, Santo Antônio de Jesus, Ilhéus-Itabuna and Vitória da Conquista.

Again, considering the extension of the model for the region of Jaborandi Solar Power Plant, it can be said that the Plant is in an intermediate suitability site, where the values of the classes vary between 3 and 4 .

The results found for Scenario 3 are shown in Figure 17.
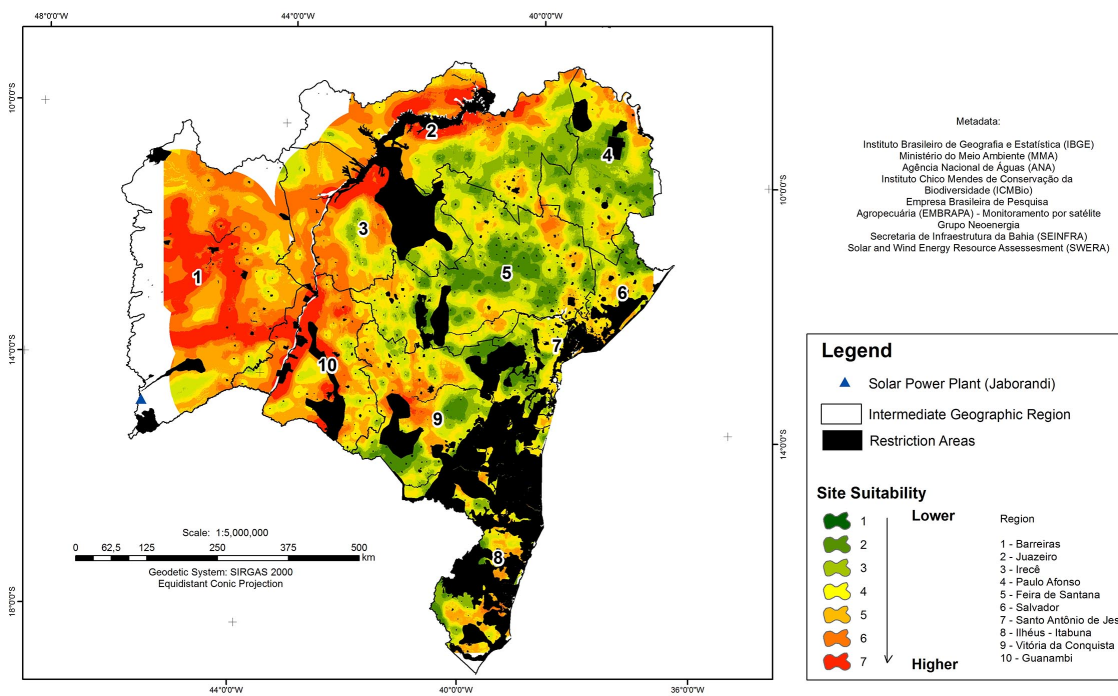

Figure 16. Map of Site Suitability-Scenario 2.
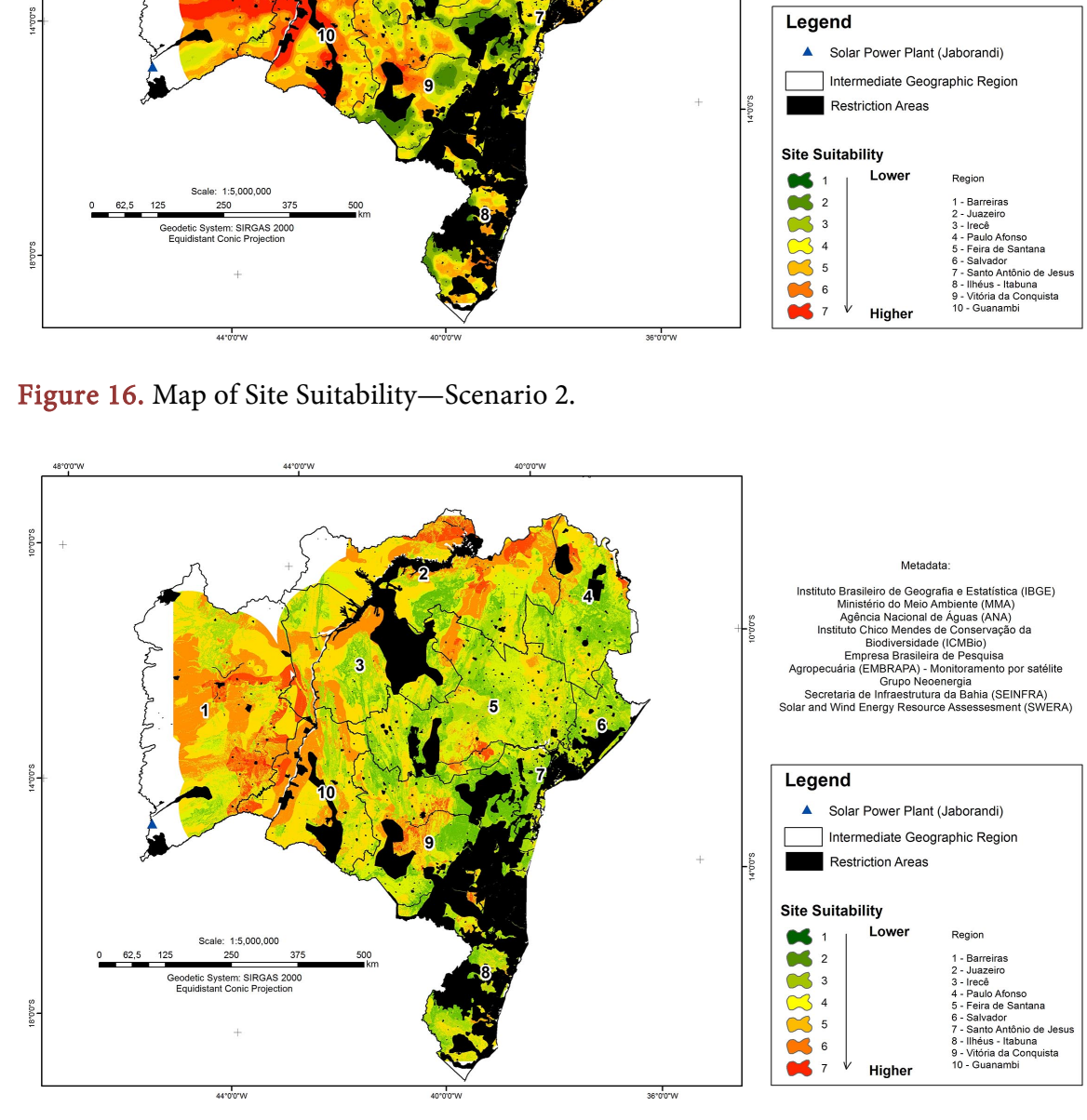

Figure 16. Map of Site Suitability-Scenario 2.

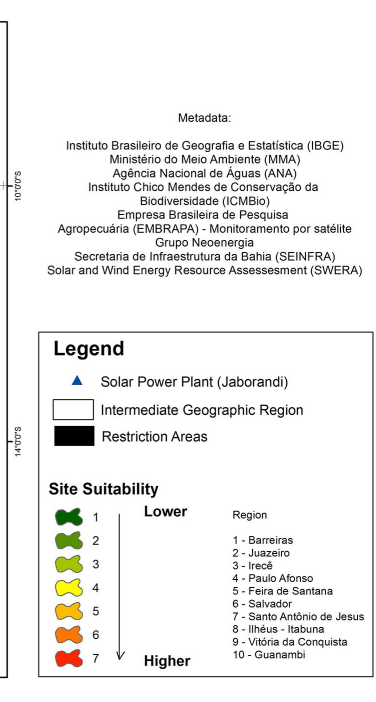

Figure 17. Map of Site Suitability—Scenario 3. 
Looking at the Map in Figure 17 and comparing it to the Map in Figure 14, it is verified that the sites with high suitability (classes 7 and 6) suffered a decrease while the sites with intermediate suitability (classes 4 and 5) became more prevalent in the State. Also, it is possible to notice that many sites that presented low suitability classes (classes 1, 2 and 3 ) now present suitability values considered intermediate.

Still, considering the extension of the model for the region of Jaborandi Solar Power Plant, it can be said that the Plant is in a site of intermediate suitability (classes 4 and 5), where the values of the classes vary between 3 and 4 .

\subsection{Final Evaluation of the Scenarios}

Considering the analysis performed, it was possible to establish suitable environments for the installation of solar thermal power plants in the State of Bahia: the IGR of Barreiras, Juazeiro, Irecê and Guanambi. All of them, without exception, presented high potential for the installation in all scenarios of the study (Starting Point Scenario, Scenario 1, Scenario 2 and Scenario 3).

Since the Starting Point Scenario, where the weightings were not considered in the identification of the suitable sites, the greater availability of high suitability sites (class 7) in the State of Bahia was found in these four IGR. This picture was repeated in the other scenarios, presenting, however, distinct characteristics.

In Scenario 1, for example, high suitability classes (classes 7 and 6) still concentrate in the western and northern regions of the State, especially in the IGR of Barreiras, Juazeiro, Irecê and Guanambi, but covering a larger number of locations when compared to the Starting Point Scenario. This is because in Scenario 1, the direct normal solar irradiation (Climatic criteria) presented a higher weight, compared to the other layers of the study, which results in the inclusion of locations with high levels of direct normal solar irradiation in the very high suitability groups.

In Scenario 2, the situation presented itself very similar to Scenario 1. In Scenario 2, the direct normal solar irradiation (Climatic criteria) presented, again, the higher weight against other layers in the study. The second higher weight was given to the elements of infrastructure (Location criteria). In this configuration, the high suitability sites (classes 7) were enlarged and focused in the eastern portion of the State, covering the IGR of Barreiras, Juazeiro, Irecê and Guanambi. The sites in the northern portion of the State, in these same IGR, that presented high suitability in the previous scenarios, now present intermediate suitability (classes 4 and 5). This happened because, when we consider the smaller distances set of information to the power lines, main road and water resources layers, the western region of the State is the one that provides the best site suitability when compared to the other regions of the State.

In the last scenario of the study, Scenario 3, the Environmental criteria presented the higher weight against the other criteria in the study. In this configuration, the high suitability sites (classes 7 and 6) also concentrated in the IGR of 
Barreiras, Juazeiro, Irecê and Guanambi, however they suffered a decrease in terms of number of locations. In this reality, these sites started to present an intermediate suitability (classes 4 and 5). This occurred because, in this configuration, the model "tended" to "pull" the sites classified as "low" and "very low" agricultural suitability to a high suitability group (classes 7 and 6), leaving the sites of "medium to high" agricultural suitability in the low suitability group (classes 1,2 and 3).

The sites located in the south of the State did not present, in any of the scenarios of the study, much availability for the installation of projects since the site suitability found there was low in all scenarios (classes 1, 2 and 3). In addition, it is important to highlight that, regardless of the values associated to suitability classes, this region would be inadequate for the installation of projects because many of its sites are occupied by restriction areas.

In all the scenarios in this study it was also seen that the region of Jaborandi Solar Power Plant is not covered by the model. This happened due to the absence of spatial information (and interpolated) of some layers in the region. However, when considering the extension of the model for the region, in all scenarios, it can be said that the Jaborandi Solar Power Plant is inserted in a region of intermediate suitability, where the values of the classes vary between 3 and 4.

Analyzing the individual suitability in the layers defined in this study, it is seen that the region where Jaborandi Solar Power Plant is situated presents good characteristic for the installation of solar power plants; the direct normal irradiation values are of the order of 5.3 to $5.8 \mathrm{kWh} / \mathrm{m}^{2}$.day (annual average). The slope of the land found in the range of $0 \%-2 \%$, which satisfies a great condition for the installation of projects. The distances to permanent water resources are of the order of $(0-15 \mathrm{~km})$. This same distance interval is seen for the power line feature. The distance to the main urban centers of the State of Bahia is also considered great and the region is situated in a low agricultural potential area, with no restrictions observed regarding land use. On the other hand, Jaborandi Solar Power Plant is located in a region with distances of $60-75 \mathrm{~km}$ to the main roads (state and federal). Such characteristic may have "pulled" the region into an intermediate classification in all scenarios of the study, even in the Starting Point Scenario, where the weights were not considered.

\subsection{Model Validation}

The model validation process for this study was performed from the pixel-to-pixel validation techniques and visual comparison and analysis. In the pixel-to-pixel validation, the thematic layers of the model were visualized in the final map of suitability and also in other cartographic documents to evaluate whether their positions match. In the process of visual comparison and analysis, the relation between the weights assigned to the layers and the final suitability of the sites were analyzed to verify the consistency of the weights in the final map 
of suitability. Such techniques were applied for the IGR of Barreiras, which presented high potential for the installation of solar power plants, according to the analyses performed. An illustration of the validation process is presented in Figure 18.

Observing the available Satellite image and the Intermediate Geographic Region and Immediate Geographic Regions Map from IBGE, it was possible to verify the coincidence between the thematic layer position of main roads and the limits between neighboring IGR. With the IBGE Map, it was also possible to observe the toponymy and other neighborhood elements (streams, localities, among others) in the region. For the urban areas and urban expansion areas, it was not possible to check the coincidence of their position because of the satellite image resolution.

To evaluate the influence of weights on the thematic layers in the definition of the final map of suitability in Barreiras, a comparison of obtained results was carried out in the Scenario 1 with the characteristics of this IGR: The solar irradiation thematic layer for Barreiras indicates that the region presents values above $5.0 \mathrm{kWh} / \mathrm{m}^{2}$.day (annual average) in all of its territory. In the eastern portion, the irradiation value is defined in the range 5.9 to $6.3 \mathrm{kWh} / \mathrm{m}^{2}$.day (annual average), what also favors the installation of solar power plants. In the scenario 1 , the solar irradiation was the parameter with greater importance, its weight was of $42 \%$. The terrain slope layer in Barreiras shows that this IGR provides land with slopes lower than $5 \%$ in various regions of its territory. Lower slopes favor the installation of solar power plants. The slope layer was the second in order of importance, presenting the percentage of $26 \%$.

Regarding land use, it is verified that the larger part of the territory of Barreiras is constituted of land with low of very low suitability, which is the agricultural potential class that most favors the installation of solar power plants in the State. This parameter had weight of $18 \%$, third in order of importance. And finally, regarding the infrastructure aspects for the interconnection of the solar power plant, it is verified that the IGR provides electric interconnection, water interconnection and road infrastructure in its central portion. Considering that all the thematic layers presented the most favorable conditions for the location of solar power plants, individually, it was verified that their aggregation, along with their respective weights (pixel resulting from the final map), returned the generation of high suitability values for the intended purpose.

\section{Conclusions}

This article presented the results of the application of AHP methods for the location of parabolic trough solar thermal power plant of $80 \mathrm{MW}$ in the State of Bahia. Based on the performed analysis, it was verified that the location based on AHP method showed to be very adequate in providing subsidies aimed at the identification of potential sites. Also, it was confirmed that the State presents high potential for the development of solar thermal technology, especially in the 

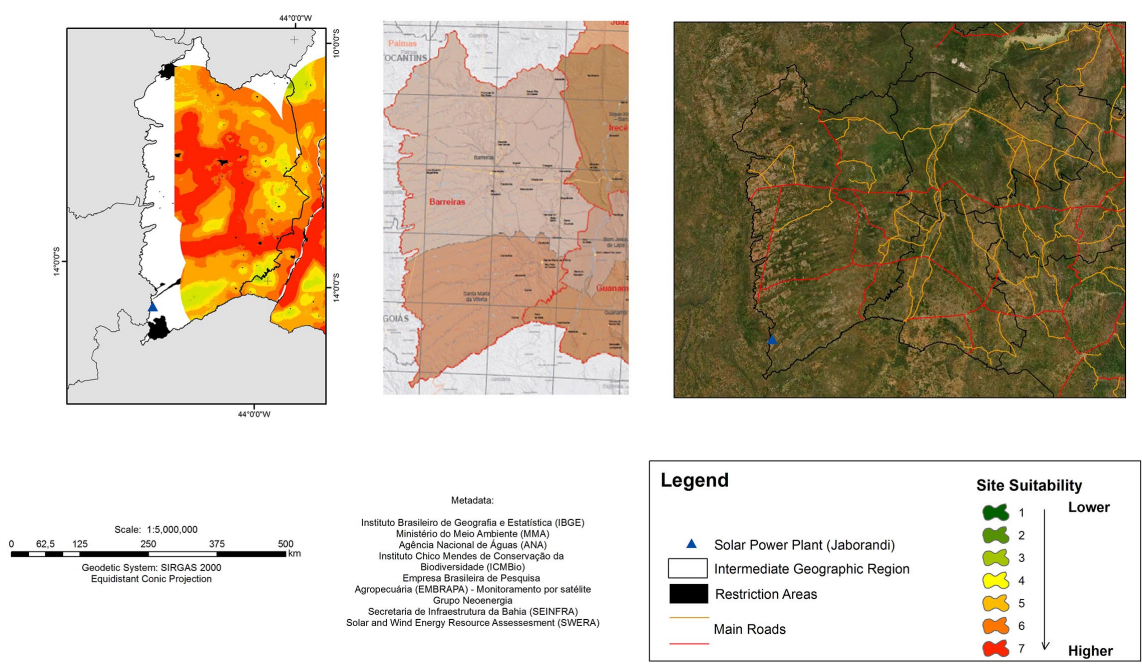

Figure 18. Model validation map.

Intermediate Geographic Regions (IGR) of Barreiras, Juazeiro, Irecê and Guanambi, where the most suitable environments for installation were found in the scenarios evaluated in the study.

Since the evaluation of the Starting Point Scenario, where the weights were not considered in the identification of suitable sites, it was observed that the greater availability of high suitability sites (class 7 ) in the State of Bahia was found in these four IGR. This picture was repeated for the other scenarios, presenting, however, distinct characteristics. In contrast, the sites located in the southern region of the State did not present, in any of the scenarios in the study, much suitability for the installation of projects, since the site suitability found there showed itself to be low in all the scenarios (classes 1, 2 and 3). In addition, it is important to highlight that, regardless of the values associated with the suitability classes, this region would show itself to be unsuitable for the installation of projects because many of its sites are occupied by restriction areas.

The validations performed in the model aimed to verify if the system developed with the help of GIS corresponded, in fact, to a relevant representation of the real world, being performed for the IGR of Barreiras. The processes applied comprised the pixel-to-pixel validation techniques and the visual comparison and analysis. Such processes demonstrated that the model used met the proposed objective, once the spatial position and other relevant information for some thematic layers, based on the Cartographic Documents available for the region, were confirmed. The validation processes also evidenced the consistency present between the weights assigned to the thematic layers individually and the final Map of sites suitability, where the thematic layers were added with their respective weights.

It is important to remember that the result of a GIS based analysis depends intrisically on the thematic layers used. If low quality spatial data are used, mistaken simplifications of reality may be generated, which will cause doubts and or uncertainties in the interpretation of the final results. Therefore, the use of high 
quality spatial data will tend to provide more faithful and accurate representations of reality.

As a suggestion for future works, in order to improve the application of this methodology, it is proposed the conduction of new analyses with the incident direct normal solar irradiation, measured for at least five years; the evaluation of sites suitability without considering the water availability aspect for the plant, in the case of the possibility of using dry cooling systems in the solar power plants; and the on-site visit to ascertain the answers found by the GIS application.

\section{Acknowledgements}

We thank the Conselho Nacional de Pesquisa (CNPq) Grant No. 302251-2017-0; P\&D ANEEL 2290-0051/2016: Desenvolvimento de Tecnologia Nacional de Geração Heliotérmica de Energia Elétrica, Termopernambuco S.A and Universidade Federal de Pernambuco, for supporting the material means and the scientific environment for the execution of this research.

\section{Conflicts of Interest}

The authors declare no conflicts of interest regarding the publication of this paper.

\section{References}

[1] Cavalcanti, E.S.C. and Petti, A.C.G. (2008) Assessment of SEGS-Like Power Plants for the Brazilian Northeast Region. Journal of Solar Energy Engineering, 130, Article ID: 014501. https://doi.org/10.1115/1.2807208

[2] Tiba, C., Fraidenhaich, N. and Barbosa, E.M.S. (2010) SIGA SOL 1.0 Sistema de Informação Geográfica Aplicada à Energia Solar. Revista Brasileira de Energia Solar, $1,149-160$.

[3] Lodi, C. (2011) Perspectivas para a Geração de Energia Elétrica no Brasil Utilizando a Tecnologia Solar Térmica Concentrada. Federal University of Rio of Janeiro, Rio of Janeiro.

[4] Azevêdo, V.W.B. and Tiba, C. (2013) Location of Large-Scale Concentrating Solar Power Plants in Northeast Brazil. Journal of Geographic Information System, 5, 452-470. https://doi.org/10.4236/jgis.2013.55043

[5] Azevêdo, V.W.B. (2016) Estudo de Localização de Usina Solar Termoelétrica no Estado de Pernambuco. Ph.D. Thesis, Federal University of Pernambuco, Recife.

[6] Zambon, K.L., Carneiro, A.A.F.M. and Negri, J.C. (2005) Análise de Decisão Multicritério na Localização de Usinas Termoelétricas Utilizando SIG. Revista Pesquisa Operacional, 25, 183-199. https://doi.org/10.1590/S0101-74382005000200002

[7] Sánchez-Lozano, J.M., García-Cascales, M.S. and Lamata, M.T. (2013) Decision Criteria for Optimal Location of Solar Plants: Photovoltaic and Thermoelectric. In: Cavallaro, F., Eds., Assessment and Simulation Tools for Sustainable Energy Systems. Green Energy and Technology, Springer, London, 79-91. https://doi.org/10.1007/978-1-4471-5143-2_4

[8] Sánchez-Lozano, J.M., Teruel-Solano, J. and Soto-Elvira, P.L. (2013) Geographical Information Systems (GIS) and Multi-Criteria Decision Making (MCDM) Methods 
for the Evaluation of Solar Farms Locations: Case Study in South-Eastern Spain. Renewable and Sustainable Energy Reviews, 24, 544-556. https://doi.org/10.1016/j.rser.2013.03.019

[9] Sanchez-Lozano, J.M., Henggeler Antunes, C. and Garcia-Cascales, M.S. (2014) GIS-Based Photovoltaic Solar Farms Site Selection Using ELECTRE-TRI: Evaluating the Case for Torre Pacheco, Murcia, Southeast of Spain. Renewable Energy, 66, 478-494. https://doi.org/10.1016/j.renene.2013.12.038

[10] Sánchez-Lozano, J.M., García-Cascales, M.S. and Lamata, M.T. (2016) GIS-Based Onshore Wind Farm Site Selection Using Fuzzy Multi-Criteria Decision Making Methods. Evaluating the Case of Southeastern Spain. Applied Energy, 171, 86-102. https://doi.org/10.1016/j.apenergy.2016.03.030

[11] Arán Carrión, J., Espín Estrella, A.F. and Aznar Dols, F. (2008) Environmental Decision-Support Systems for Evaluating the Carrying Capacity of Land Areas: Optimal Sites Selection for Grid-Connected Photovoltaic Power Plants. Renewable and Sustainable Energy Reviews, 12, 2358-2380.

https://doi.org/10.1016/j.rser.2007.06.011

[12] Saaty, T.L. (1980) The Analytic Hierarchy Process: Planning, Priority Setting, Resource Allocation. McGraw-Hill, New York, 437.

https://doi.org/10.21236/ADA214804

[13] Saaty, T.L. (1991) Método de Análise Hierárquica. Makron Books, São Paulo, 367.

[14] Ribeiro, G.P. (2005) Tecnologias Digitais de Geoprocessamento no Suporte à Análise Espaço-Temporal em Ambiente Costeiro. Ph.D. Thesis, Federal University Fluminense, Rio de Janeiro.

[15] Medeiros, J.S. (1997) Bancos de Dados Geográficos e Redes Neurais Artificiais: Tecnologias de Apoio à Gestão do Território. Ph.D. Thesis, Federal University of São Paulo, São Paulo.

[16] Mennis, J., Viger, R. and Tomlin, C.D. (2005) Cubic Map Algebra Functions for Spatio-Temporal Analysis. Cartography and Geographic Information Science, 32, 17-32. https://doi.org/10.1559/1523040053270765

[17] Barbosa, C.C.F. (1999) Álgebra de Mapas e suas Aplicações em Sensoriamento Remoto e Geoprocessamento. Master, National Institute for Space Research.

[18] Junges, L.C.D. (2006) Introdução a Lógica Fuzzy. Departamento de Automação de Sistemas Industriais Inteligentes.

[19] Burrough, P.A. and Mcdonnel, R.A. (1998) Principles of Geographical Information Systems. Clarendon Press, Oxford, 311.

[20] Zadeh, A. (1965) Fuzzy Sets. Information and Controls, 8, 338-353. https://doi.org/10.1016/S0019-9958(65)90241-X

[21] Eastman, J.R. and Jiang, H. (1996) Fuzzy Measures in Multi-Criteria Evaluation. 2nd International Symposium on Spatial Accuracy Assessment in Natural Resources and Environmental Studies. GIS World, 527-534.

[22] Broesamle, H., Mannstein, H. and Schillings, C. (2001) Assessment of Solar Electricity Potentials in North Africa based on Satellite Data and a Geographic Information System. Solar Energy, 70, 1-12. https://doi.org/10.1016/S0038-092X(00)00126-2

[23] Dahle, D., Elliott, D. and Heimiller, D. (2008) Assessing the Potential for Renewable Energy Development on DOE Legacy Management Lands. National Renewable Energy Laboratory (NREL), Golden. 